UDC 821.161.1-31.09 Dostoevskij F. M. https://doi.org/10.18485/ms_zmss.2021.99.6

\author{
Лиана Димитриева \\ Независимый исследователь, Санкт-Петербург \\ lianaponomar@gmail.com \\ Liana Dimitrieva \\ Independent Scholar, S.-Peersburg \\ lianaponomar@gmail.com
}

\title{
ДОСТОЕВСКИЙ И ДЕНЬГИ: ФОКУС ВНИМАНИЯ ФРАНЦУЗСКОЙ СТОРОНЫ ${ }^{1}$
}

\author{
DOSTOEVSKY AND MONEY: \\ THE FOCUS OF ATTENTION OF THE FRENCH PARTY
}

В статье разбирается роль денег в творчестве Достоевского вслед за тремя работами французских славистов: Софи Олливье, Жака Катто и Карен Аддад. Всю жизнь работавший за гонорар, Достоевский действительно был уникальным писателем, которого обеспечивало ремесло. Деньги были для него одновременно средством к существованию, возможностью продолжения работы, помехой для творчества (из-за сроков и поэтапной печати текстов Достоевский находился в постоянной спешке) и его стимулом, поскольку вынуждали писателя перейти от скрупулёзной работы над замыслом к его воплощению. Ни у самого писателя, ни у его персонажей деньги не «водятся»: герои Достоевского чрезвычайно успешно прогуливают, проматывают и пропивают капитал вне зависимости от его объёма. Сам Достоевский как игрок имеет опыт игры как зрелища исчезновения денег. Исследователи отмечают уничтожение денег как устойчивый образ, реализующийся в текстах писателя в различных вариациях. Вместе с тем игра и творчество метонимически связаны для Достоевского, и исследователи обращают внимание на писательский азарт Достоевского и на то, как творчество замещает и вытесняет собой игру. Отношение героев Достоевского к деньгам - своего рода приём, позволяющий писателю быстро и точно охарактеризовать персонажей. Отношение Достоевского к деньгам проблематично и амбивалентно: всю жизнь стремясь заработать денег, писатель отрицательно относится к накоплению капитала. При этом Достоевскому явно присуще экономическое мышление. Тема денег, как и тема игры, связана в творчестве писателя и с русской идеей. Плотно переплетены деньги и с эросом - с одной стороны, и с творчеством - с другой. Эти особенности биографии и творческого процесса писателя делают деньги одной из стихий его произведений.

Ключевые слова: Достоевский, деньги, игра, русская идея, Подросток, Софи Олливье, Жак Катто, Карен Аддад.

1 Исследование выполнено при финансовой поддержке гранта РФФИ № 18-0129001: «Междисциплинарная рецепция творчества Ф. М. Достоевского во Франции 1968-2018 годов: филология, философия, психоанализ». 
The article examines the role of money in Dostoevsky's work following three works by French Slavists: Sophie Ollivier, Jacques Catteau and Karen Addad. Having worked all his life for a fee, Dostoevsky really was a unique writer who himself provided through writing. For him, money was at the same time a means of subsistence, an opportunity to continue work, an obstacle to creativity (due to the timing and stage-bystage printing of texts, Dostoevsky was in a constant rush) and its stimulation, since it forced the writer to move from scrupulous work on the idea to its implementation. Neither the writer himself nor his characters ever actually have money: Dostoevsky's heroes are extremely successful in wasting fortunes, regardless of their volume. Dostoevsky himself as a gambler, has seen money disappear during the game. Researchers mark the vanishment of money as a stable image that is realized in the writer's texts in various variations. At the same time, gambling and creativity are metonymically linked for Dostoevsky, and researchers draw attention to Dostoevsky's passion for writing and how creativity eventually replaces gambling. The attitude of Dostoevsky's heroes to money is a kind of technique that allows the writer to depict his characters quickly and accurately. Dostoevsky's attitude to money is problematic and ambivalent: all his life, striving to make money, the writer has a negative attitude towards the accumulation of capital. At the same time, economic thinking is clearly inherent in Dostoevsky. The theme of money, like the theme of gambling, is connected in the writer's work with his Russian idea. Money is tightly intertwined with eros, on the one hand, and with creativity, on the other. These features of the biography and creative process of the writer make money one of the key elements of his works.

Key words: Dostoyevsky, money, gambling, the Russian idea, the Adolescent, Sophie Ollivier, Jacques Catteau, Karen Haddad.

Тема денег, несомненно, важна в жизни Достоевского как человека и как писателя. Французские литературоведы не обошли эту тему вниманием: Софи Олливье 2 затронула её одной из первых, затем Жак Катто, один из самых авторитетных славистов, посвятил ей главу в своей книге $^{3}$, наконец, в 2014 году вышла работа Карен Аддад 4 на эту же тему.

Все три исследователя отталкиваются в своих размышлениях именно от понятия «литератор-пролетарий», которое применяет к себе Ф. М. Достоевский в письме Н. Н. Страхову от 18 (30) сентября 1963 года: «NB. Пусть знает Боборыкин, так же как это знают “Современник” и “Отеч<ественные> записки", что я еще (кроме “Бедных людей”) во всю жизнь мою ни разу не продавал сочинений, не брав вперед деньги. Я литератор-пролетарий, и если кто захочет моей работы, то должен меня вперед обеспечить. Порядок этот я сам проклинаю. Но так завелось и, кажется, никогда не выведется» (Достоевский 1985б: 50).

Во французской литературе сопоставимое внимание деньгам уделяет разве что Бальзак. Карен Аддад обращает внимание, что эту анало-

2 Ollivier Sophie. «L'argent chez Dostoievski». Europe. Revue littéraire mensuelle. Octobre 1971: 70-83.

3 Catteau Jacques. «L'argent». Catteau Jacques. La création littéraire chez Dostoïevski. Paris: Institut d'études slaves, 1978: 181-222.

4 Haddad Karen. «La liasse manquante. Quelques remarques sur l'argent chez Dostoïevski». La littérarure au prisme de l'économie. Argent et roman en France au XIX siècle. Paris: Classiques Garnier, 2014: 233-245. 
гию проводит ещё Марсель Пруст, сравнивая письма Достоевского с письмами Бальзака: те же требования денег, обещания отплатить с гонорара в случае успеха... (Haddad 2014: 234). Но, как отмечает Софи Олливье, Бальзака не волнует, как бы избавиться от власти денег. Наоборот, он проводит целое исследование законов укрощения этой стихии (Ollivier 1971: 83).

Случай Достоевского оригинален сам по себе, но он завораживает французских исследователей во многом именно благодаря этому контрасту с Бальзаком, роман которого Евгения Гранде Достоевский переводил в юности, и влияние которого как на Достоевского-читателя, так и на Достоевского-писателя, несомненно, велико.

Для Достоевского писательское ремесло - не только призвание, но и единственный источник дохода. Жак Катто возводит взаимоотношения писателя с деньгами в ранг творческого метода, выстраивая структуру из двух симметричных параграфов «Творческий процесс и деньги: обвинение» и «Творческий процесс и деньги: защита». Слова «обвинение» и «защита» относятся, разумеется, к деньгам, и если с ролью обвинителя прекрасно справляется и сам Достоевский, то в качестве адвоката денег выступает Катто. Суть этого фантастического процесса в следующем.

С одной стороны, мало того, что Достоевский вынужден продавать издателям «идею», «замысел» и существовать в состоянии вечного ожидания аванса, ему и платят за печатный лист меньше, чем Тургеневу, Толстому, Гончарову — писателям, не связанным подобными обязательствами с издателями, которые боролись за их готовые тексты. (Catteau 1978: 195) Это вынуждало Достоевского работать в спешке, зачастую не перечитывая и не прорабатывая текст стилистически в той мере, в какой ему бы хотелось. Он часто выражает опасение, что испортит замысел - и столь же часто бывает неудовлетворен результатом работы. В воспоминаниях Анны Григорьевны Достоевской постоянные долги выступают, во-первых, как экономическая катастрофа, потому что Достоевский вынужден был соглашаться на несправедливую оплату своего труда - и из-за этого называл свой труд каторжным, сравнивал свою работу с кабалой. А во-вторых, долги несут катастрофические последствия в эстетической сфере: спешное письмо обречено на несовершенство, тяжеловесность. Конечно, в словах супруги писателя слышится эхо слов самого Достоевского, который приводил те же аргументы, как бы оправдываясь в ответ на упрёки критиков (Catteau 1978: 194-197).

С другой стороны, вопреки тому, что Достоевский действительно борется за выживание и часто ссылается на свою участь бедного писателя, его далеко нельзя отнести к тем бедным людям, каковыми являются его герои. Достоевский же мог голодать, но как только появлялись деньги, угощал друзей; едва платил за жильё, но регулярно переезжал в более просторные и светлые квартиры; ухаживал за рединготом, чтобы 
он дольше прослужил, но одевался у дорогого портного (Catteau 1978: 198). Вспомним знаменитый пассаж из романа Подросток, размышление Аркадия Долгорукого, который собирается «сделаться Ротшильдом»: «...чтобы платье было всегда ново и не изнашивалось, надо чистить его щеткой сколь возможно чаще, раз по пяти и шести в день. Щетки сукно не боится, говорю достоверно, а боится пыли и сору. Пыль - это те же камни, если смотреть в микроскоп, а щетка, как ни тверда, все та же почти шерсть. Равномерно выучился я и сапоги носить: тайна в том, что надо с оглядкой ставить ногу всей подошвой разом, как можно реже сбиваясь набок. ... Этим способом сапоги носятся, в среднем выводе, на треть времени дольше» (Достоевский 1975: 69).

Катто приводит суммы, полученные Достоевским от издателей, и оказывается, что литератор-пролетарий зарабатывает немало (Catteau 1978: 198). В чём же причина того, что писатель вечно нуждается, что деньги словно ускользают у него сквозь пальцы? Помимо непрактичности, легковерности, расточительности и щедрости, свойственных Достоевскому, Катто называет ещё одну причину, и весьма интересную: подсознательную контрреакцию на скупость своего отца, Михаила Андреевича Достоевского (200). В самом деле, Достоевский с юности привык просить деньги. Во время обучения в Инженерном училище его письма к отцу пестрят просьбами о деньгах, самые трогательные из них просьбы денег на собственный чай 5 . Потом он этот чай подарит своему первому герою, Макару Девушкину из романа Бедные люди 6 . Это мотив будет актуален и в Записках из мёртвого дома7. Позже подпольный парадоксалист тоже будет видеть в этом собственном чае символ независимости ${ }^{8}$.

И ещё один околопсихоаналитический аргумент в пользу денег: Катто отмечает, что Достоевский играет в литературу, как в рулетку и выигрывает. Прекрасным примером тому служит пари с издателем Стелловским, в результате которого роман Игрок был написан за 28 дней (Catteau 1978: 184-187). Но и в других случаях аванс связывает Достоевского с издателем обязательством, подобным возгласу «ставки сделаны, ставок больше нет»: ему ничего не остаётся, кроме как писать без передышки (Catteau 1978: 188). Рулетка и письмо имеют много общего: мотивация заработать денег, тяга к риску, страстное желание склониться над бездной. С этой сладострастной тягой к риску Катто связывает между прочим и склонность писателя к женщинам гораздо моложе него самого (Catteau 1978: 190).

5 «Но всё-таки я, уважая Вашу нужду, не буду пить чаю» (Достоевский 1985a: 60).

6 «...чаю не пить как-то стыдно» (Достоевский 1972а: 17).

7 «Между прочим, они научили меня, что должно иметь свой чай, что не худо мне завести и чайник...» (Достоевский 1972б: 25).

8 «Свету ли провалиться, или вот мне чаю не пить? Я скажу, что свету провалиться, а чтоб мне чай всегда пить» (Достоевский 1973: 174). 
Но и в игре, и в ремесле отношение Достоевского к деньгам парадоксально. Олливье отмечает первой (с ней согласны и другие исследователи), что нуждающийся в деньгах писатель, получив их - даром или трудом, - как бы стремится немедленно от них избавиться. В игре есть сладострастное удовольствие - видеть, как деньги исчезают. Достоевский словно любит эти безвыходные ситуации, когда он оказывается на краю бездны с душераздирающим воплем: «у меня нет ни копейки» (Ollivier 1971: 70). Возможно, предполагает Катто, эта вечная нехватка денег - скорее следствие натуры Достоевского, чем сознательно принятый им метод литературной работы. В природе Достоевского - тяготеть к плодотворной нестабильности желания. Возможно, он и вовсе не смог бы работать в других условиях (Catteau 1978: 200).

Что касается невозможности перечитывать написанное и оттачивать стиль из-за постоянной спешки, Достоевский признавался, что вовсе теряет способность к критическому взгляду на свои готовые тексты, и, хоть и перечитывал их впоследствии, никогда ничего по-крупному не менял. Причина многословия, за которое себя упрекает писатель, в том, что он постоянно возвращался к излюбленным темам до полного их истощения. Показателен случай со «сном о золотом веке»: дорогой ему замысел Достоевский всё-таки перенёс из главы «У Тихона», не вошедшей в текст романа Бесы, в роман Подросток. Всё это не свидетельствует о том, что Достоевский не способен перерабатывать свои тексты. Катто видит здесь причину в специфике полифонического романа, подразумевающего страстный процесс письма, со свойственным ему затягиванием не-разрешения конфликта до бесконечности (Catteau 1978: 200-202). Поэтому деньги играют здесь решающую роль: они вынуждают к переходу от замысла к его исполнению, переходу тем более болезненному, что воплощение идеи никогда не приносит полного удовлетворения, и замысел всегда кажется больше реализованного. О природе письма много, пусть и наивно, размышляет Аркадий Долгорукий: «Я перечел теперь то, что сейчас написал, и вижу, что я гораздо умнее написанного» (Достоевский 1975: 6).

Софи Олливье выстраивает вокруг оси отношения к деньгам всю систему персонажей Достоевского. По её типологии, герои Достоевского делятся на различные категории по следующим критериям: стремление к накоплению, презрение к деньгам, цель, для которой персонажу нужны деньги. В галерее персонажей есть те, чья единственная цель заработать деньги: ростовщики, купцы (впрочем, их как раз очень мало), предприимчивая знать. Деньги могут быть способом достичь внутреннего равновесия и осознания собственной ценности (Аркадий Долгорукий, Голядкин, генерал Иволгин). Одним персонажам деньги нужны, чтобы освободиться из унизительного положения (Грушенька, Голядкин, Прохарчин), другие копят из соображений скупости и эгоизма (как Федор Карамазов). То есть деньги представляются ещё и неким поэтиче- 
ским инструментом, писательским приёмом Достоевского, с помощью которого он даёт читателю понять, что за персонаж перед ним (Ollivier 1971: 72-76).

И однако же, все сходятся на том, что в поэтике Достоевского единственный вызывающий симпатию способ обогащения - игра. Она наименьшее из зол, поскольку в меньшей степени способствует деградации, в отличие от накопительства или преступной наживы. Но тут мнения исследователей расходятся: Катто относит выигрыши наравне с полученным наследством (ещё один повторяющийся мотив Достоевского, и, как правило, речь идёт о баснословных суммах) - к категории денег, свалившихся с небес. Однако Олливье обращает внимание на сложную систему, разработанную героем романа Игрок. Игра - это не просто воля случая. Это стратегия.

Катто считает Достоевского наивным в экономическом плане (Catteau 1978: 215), в качестве доказательства приводя в пример утопические картины общества без денег, которые рисуются в Сне смешного человека или в «золотом веке» Версилова. Олливье же рассматривает Достоевского как, пусть и бывшего, но социалиста, и, несмотря на консерватизм его последних лет, убеждённого антикапиталиста. В своей статье она указывает на то, что по одним текстам Достоевского, даже не прибегая к документальным источникам, можно проследить современное ему развитие капитализма в России, признаки медленного наступления которого становятся важными мотивами в текстах Достоевского: появление железных дорог, отмена крепостного права. Кроме того, материальный мир его произведений осязаем: мы знаем, кто сколько получает и что сколько стоит. Уже начиная с «Зимних заметок о летних впечатлениях» Достоевский развивает антикапиталистическую тему, вокруг которой впоследствии строятся большие романы: критика капиталистического общества Англии, анализ социально-экономической ситуации во Франции, ужас перед французским буржуа и его мечтой сколотить состояние, будучи честным человеком (Ollivier 1971: 76-78). Добавим, что в Дневнике писателя Достоевский, безусловно, развивает социальную, политическую и экономическую рефлексию. И, разумеется, не будем забывать о предпринимательской деятельности Достоевского, управлявшего журналами Время и Эпоха. Всё это свидетельствует во всяком случае о развитом экономическом мышлении.

Тема денег связана у Достоевского и с мессианским пафосом внутри дискурса «Россия и Запад»: вслед за французским буржуа, вспомним тут и «немецкий способ» обогащения - систематическое накопление, отвращение и презрение к которому часто высказывает Достоевский. Аддад отмечает, что эта позиция сопровождается и антисемитизмом: хоть и далеко не все ростовщики у Достоевского обязательно евреи, так или иначе происходит перенос этого термина на всех, в ком писатель видит экономическую угрозу России (Catteau 1978: 234). Олливье, рассуждаю- 
щая об апокалиптическом видении капиталистических процессов, также отмечает, что Достоевский возлагает особую миссию по спасению мира с помощью русского духа, чья особенность раскрывается в том числе в связи с рулеткой, в самом принципе которой Достоевскому видится нечто родственное, свойственное русскому человеку, антикапиталисту по природе (Ollivier 1971: 73-74, 78).

Безусловно, во вселенной Достоевского важно эротическое измерение денег. Речь идёт не только о том, с каким сладострастьем герои проматывают крупные суммы. Сами деньги эротизированы до той степени, когда они перестают быть равными себе. Аддад ставит в центр своего рассуждения образ пропавшей, исчезнувшей, недостающей пачки денег, вожделенной, желанной, приковывающей взгляды. Она сравнивает две таких пачки. Первая - это те 100 тысяч, которые в ходе торговли Настасьей Филипповной она сама же бросает в камин. Пачка обёрнута в Биржевые ведомости и речь о ней идёт не как о деньгах, скорее даже как о чём угодно, кроме денег. Окружающие смотрят на несгораемую, невредимую, неопалимую пачку в огне со священным ужасом и благоговением. Ганя, бледный, не сводит с неё глаз. Когда пламя касается пачки, все в ужасе кричат: «горит! горит!» словно речь идёт о человеческой жертве. При этом деньги максимально отчуждены, и доказательство тому — тот факт, что Достоевский больше эти 100 тысяч не вспоминает (Haddad 2014: 237). Инверсию этой ситуации находим в Братьях Kapaмазовых: дело вновь в пачке денег, но теперь в пачке пропавшей, отсутствующей (ср. название одной из глав романа: «Денег не было. Грабежа не было»). Сцена, когда Смердяков показывает Ивану ту самую пачку денег, насыщена деталями: то, как выглядит пачка и как Смердяков достаёт её из кармана - квазиэротический процесс. Но и эти деньги не имеют значения: ни Смердякову, ни Ивану, ни даже суду они не нужны. Итак, деньги никогда не важны сами по себе: они то сгорают, то пропадают. «Хорошие деньги» — лишь те, что в ходу (Haddad 2014: 239).

Вместе с тем деньги у Достоевского выступают как эквивалент творчества. Писательское ремесло монетизируется, хоть и с трудом. Однако выполненная работа равна авансу и гонорару. В этом смысле Аддад имеет в виду ещё одну пачку: пачку листов, исписанных Аркадием Долгоруким. Мечтая стать Ротшильдом, Аркадий мечтает о столь же отчуждённых деньгах, с какими мы имеем дело в Идиоте и в Братьях Kapaмазовых: «Мне не нужно денег, или, лучше, мне не деньги нужны; даже и не могущество; мне нужно лишь то, что приобретается могуществом и чего никак нельзя приобрести без могущества: это уединенное спокойное сознание силы! Вот самое полное определение свободы, над которым так бьётся мир!» (Достоевский 1975: 74).

Согласно Аддад, нечто иное, во что превращается идея Подростка, и есть письмо. Пачки купюр, которых жаждал Аркадий, замещают пачки листов, исписанные им (Haddad 2014: 243). 
Между деньгами воображаемыми и деньгами конкретными в творчестве Достоевского наблюдается такой же разрыв, как между идеей и её воплощением. Купюры, которые копятся, никогда не могут воплотить идеи богатства, подобно тому, как исписанные листы никогда не становятся главным произведением. Шедевр - как капитал - всегда только ожидается (Haddad 2014: 245).

По словам Жака Катто, Достоевский ввёл в современную историю литературы вопрос необходимости денег и вместе с тем проблематизировал вопрос их посреднической роли в творческом процессе, сделав из этого эстетический принцип. Всё творчество Достоевского сообщает нам, что деньги - это категория познания социального и даже духовного бытия (Catteau 1978: 203). Так, Софи Олливье отмечает, что, как правило, писатель питает интерес к бережливым персонажам, умеющим считать и предвидеть. Но те, как правило, беднее «растратчиков» (Ollivier 1971: 75). Согласимся с Карен Аддад в том, что накапливание в романах Достоевского не имеет положительного примера (Haddad 2014: 239). И добавим, что крупные суммы у Достоевского появляются в столь странных обстоятельствах, что их можно назвать анекдотическими, как и сами суммы - миллион, сто тысяч - словно речь идёт о фантазии человека, которому настолько несвойственно иметь деньги, что он даже не знает, как они исчисляются. Вместе с тем нельзя отказать писателю в глубоком понимании природы денег. Отношение Достоевского к деньгам амбивалентно, что не могло не отразиться на его поэтике. И примечательно, что в фокусе внимания французских исследователей в этом вопросе оказывается именно роман Подросток, где тема денег представлена наиболее парадоксально.

\section{ЛИТЕРАТУРА}

Достоевский Федор. Бедные люди. Достоевский Федор. Полное собрание сочинений. В 30 т. Т. 1. Ленинград: Наука, 1972а.

Достоевский Федор. Записки из мертвого дома. Достоевский Федор. Полное собрание сочинений. В 30 т. Т. 1. Ленинград: Наука, 1972b.

Достоевский Федор. Записки из подполья. Достоевский Федор. Полное собрание сочинений. В 30 т. Т. 1. Ленинград: Наука,1973.

Достоевский Федор. Письма. Достоевский Федор. Полное собрание сочинений. В 30 т. Т. 1. Ленинград: Наука, 1985a.

Достоевский Федор. Письма. Достоевский Федор. Полное собрание сочинений. В 30 т. Т. 1. Ленинград: Наука, 19856.

Достоевский Федор. Подросток. Достоевский Федор. Полное собрание сочинений. В 30 т. Т. 1. Ленинград: Наука, 1975.

Catteau Jacques. «L'argent». Catteau Jacques. La création littéraire chez Dostö̈evski. Paris: Institut d'études slaves, 1978: 181-222.

Haddad Karen. «La liasse manquante. Quelques remarques sur l'argent chez Dostoïevski». La littérarure au prisme de l'économie. Argent et roman en France au XIX siècle. Paris: Classiques Garnier, 2014: 233-245.

Ollivier Sophie. «L'argent chez Dostoievski». Europe. Revue littéraire mensuelle. Octobre 1971: 70-83. 


\section{LITERATURE}

Catteau Jacques. «L'argent». Catteau Jacques. La création littéraire chez Dostoïevski. Paris: Institut d'études slaves, 1978: 181-222.

Dostoevskij Fedor. Bednye lyudi. Dostoevskij Fedor. Polnoe sobranie sochinenij. V 30 t. T. 1. Leningrad: Nauka, 1972a.

Dostoevskij Fedor. Zapiski iz mertvogo doma. Dostoevskij Fedor. Polnoe sobranie sochinenij. V 30 t. T. 1. Leningrad: Nauka, 1972 b.

Dostoevskij Fedor. Zapiski iz podpol'ya. Dostoevskij Fedor. Polnoe sobranie sochinenij. V 30 t. T. 1. Leningrad: Nauka,1973.

Dostoevskij Fedor. Pis'ma. Dostoevskij Fedor. Polnoe sobranie sochinenij. V 30 t. T. 1. Leningrad: Nauka, 1985a.

Dostoevskij Fedor. Pis'ma. Dostoevskij Fedor. Polnoe sobranie sochinenij. V 30 t. T. 1. Leningrad: Nauka, 1985b.

Dostoevskij Fedor. Podrostok. Dostoevskij Fedor. Polnoe sobranie sochinenij. V 30 t. T. 1. Leningrad: Nauka, 1975.

Haddad Karen. «La liasse manquante. Quelques remarques sur l'argent chez Dostoïevski». La littérarure au prisme de l'économie. Argent et roman en France au XIX siècle. Paris: Classiques Garnier, 2014: 233-245.

Ollivier Sophie. «L'argent chez Dostoievski». Europe. Revue littéraire mensuelle. Octobre 1971: 70-83.

Лијана Дмитријева

ДОСТОЈЕВСКИ И НОВАЦ: У ФОКУСУ ФРАНЦУСКЕ СТРАНЕ

Резиме

У раду се посматра улога новца у стваралаштву Достојевског на трагу три рада француских слависта: Софи Оливје, Жака Като и Карен Адад. Радећи цео живот за хонорар, Достојевски је заиста био јединствен пример писца који је живео од заната. Новац је за њега био истовремено средство за живот, могућност продужетка посла, сметња у стварању (због рокова и штампања текстова у деловима Достојевски је стално био у цајтноту) и подстрек, будући да је управо новац приморавао писца да пређе са скрупулозног осмишљавања идеје на њену реализацију. Ни сам писац, ни његови јунаци немају новац: јунаци Достојевског изузетно успешно расипају, траће и пропијају сав капитал без обзира на његову висину. Сам Достојевски као коцкар има искуство с коцкањем као призором нестајања новца. Истраживачи истичу уништавање новца као стални мотив, који се у пишчевим текстовима остварује с различитим варијацијама. Поред тога, коцкање и стваралаштво су за Достојевског метонимијски повезани, те истраживачи скрећу пажњу на стваралачки занос Достојевског, а нарочито на чињеницу да стварање замењује и потискује коцкање. Однос јунака Достојевског према новцу је својеврстан књижевни поступак који омогућава писцу да брзо и прецизно окарактерише јунаке. Однос Достојевског према новцу је проблематичан и амбивалентан: трудећи се током читавог живота да заради новац, писац се ипак негативно односи према гомилању капитала. Притом, Достојевском је очито близак економски начин мишљења. Тема новца као и тема коцкања су у пишчевом стваралаштву повезане и са руском идејом. С једне стране, новац се преплиће с еросом, с друге - са стварањем. Ове особености пишчеве биографије и стваралачког процеса чине новац једном од стихија у његовим делима.

Кључне речи: Достојевски, новац, коцкање, руска идеја, Млаgић, Софи Оливје, Жак Като, Карен Адад. 